\title{
A Healthy Ocean Matters
}

IN DECEMBER 1968, people on Earth saw for the first time what our watery home looks like from space. The crew of Apollo 8, the first manned lunar orbital mission, not only took pictures of potential landing sites on the moon; they also sent back pictures of the distant ocean world-Earth. What became obvious from those photos is that Earth is extraordinary because of the liquid water ocean dominating the cloudshrouded surface. There is no question that the ocean, covering $70 \%$ of Earth's surface, profoundly influences the planet's biological, chemical, geological, and physical processes.

Some 40 years after Apollo 8, we have come to recognize that humans are affecting the natural processes that support life on Earth. Climate change, perhaps the greatest challenge humankind has had to face, is often equated with global warming, but perhaps Thomas Friedman better describes climate change in his book Hot, Flat, and Crowded when he refers to it as "global weirding." In addition to warming, climate change will affect everything from weather patterns to ocean chemistry. The numbers of living organisms continue to crowd the planet, with associated wastes. Also, the direct linkages between environmental health and the health of the living organisms depending on that environment have become more conspicuous.

This issue of Oceanography is devoted to one of the consequences of pumping large amounts of waste, specifically greenhouse gases, into the atmosphere-it is turning the ocean more acidic. According to a fact sheet prepared by the US National Oceanic and Atmospheric Administration (NOAA; see http:// www.pmel.noaa.gov/co2/OA/index.html), "the oceans have absorbed about $50 \%$ of the carbon dioxide released from the burning of fossil fuels, resulting in chemical reactions that lower ocean $\mathrm{pH}$. This has caused an increase in hydrogen ion[s] (acidity) of about $30 \%$ since the start of the industrial age through a process known as 'ocean acidification." NOAA cites a number of adverse impacts on marine organisms that include: (1) the decrease in the rate at which reef-building corals produce their skeletons, (2) the reduced ability of marine algae and free-swimming zooplankton to maintain their protective shells, (3) the decline of marine plankton as a vital food source in the food web of marine species, and (4) the reduced survival of larval marine species, including commercial fish and shellfish. There is growing recognition that wild animals may act as "sentinels" of environmental health, providing early warning of human health hazards, just as canaries provided for underground coal miners in years past. Are corals and other marine calcifers Earth's canaries?

Although the magnitude of the biogeochemical and biological effects and the attendant socio-economic impacts of ocean acidification are currently too uncertain to quantify, the long-term consequences for global carbon cycling and, ultimately, Earth's climate, is all but certain. The alarms being sounded about ocean health are often focused on the health of its inhabitants-marine organisms-as if humans are detached from the ecosystems upon which they too depend for health and wellbeing. We must recognize that corals and fishes are not the only living organisms suffering the consequences of society's increasing demands.

By either taking action or looking the other way, humankind will be choosing between two very different futures. At this juncture, satisfying short-term needs tends to be placed ahead of planning for future generations. Excuses for inaction abound and "politics as usual" will almost certainly guarantee failure. As history has taught us, the only defense against political inertia is offensive leadership - and in this regard ocean issues are no exception. The oceanography community must provide the needed ocean leadership - whether through conducting multidisciplinary, transformative research, educating the next generation of ocean science professionals, proactive involvement in the public policy process, or enhancing public understanding.

In this extraordinarily interdependent world, we must take the planetary view shared by the Apollo 8 astronauts when they first showed us Earth. The wellbeing of the individual and of each species is connected to the wellbeing of the whole; we all have the responsibility to care for Earth and its life-supporting systems. A healthy ocean matters-to our health, prosperity, security, and quality of life. Fundamental discoveries about the natural world open the way for an even more exciting and productive future-if we learn to operationalize what we know.

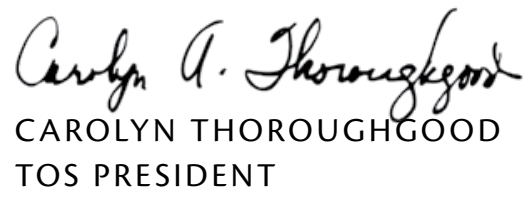

